\title{
Decompressive cervical laminectomy and lateral mass screw-rod arthrodesis: Surgical analysis and outcome
}

H.M.ELNemr, N.M.Sayed, W.B.Sharshera, M.A.ELAwady and M.M.ELMaghrabi

Neurosurgery Dept., Faculty of Medicine, Benha Univ., Benha, Egypt

E-Mail: Hanyelnemr1986@yahoo.com

\begin{abstract}
Posterior plating utilizing lateral mass screw fixation has been widely accepted for treating the unstable cervical spine caused by trauma, neoplasms, significant degenerative conditions, and failed anterior fusions. The aim of this study is to evaluate the outcome and complications of decompressive cervical laminectomy and lateral mass screw fixation in patients treated for variable cervical spine pathologies. This retrospective study was conducted on patients with unstable cervical spine in the period of two years. Patients were admitted also worked upon in the section from claiming Neurosurgery, over Banha college healing centers from October 2015 to October 2017 What's more emulated dependent upon for 12 will 18 months after the fact. Postoperatively, patient's myelopathy evaluation and practical status might have been assessed promptly then afterward operation At that point weekly for those 1st month At that point each 3 months for the 1st quite a while Furthermore each six months in the second quite a while. Assessment of the postoperative myelopathy might have been conveyed crazy instantly postoperatively What's more throughout six months utilizing Nurick's myelopathy evaluating Also neck handicap scale. Factual Investigation uncovered that there will be a noteworthy expand of situations from claiming review 1 post-operatively over the individuals pre-operatively Also a diminishing Previously, both amount from claiming situations from claiming review 2 What's more evaluation 4 post-operatively over pre-operatively. Same time other evaluations didn't demonstrate any huge transform over their figures post-operatively contrasted with their figures pre-operatively.
\end{abstract}

Keywords: Lateral mass, Cervical laminectomy, Myelopathy, Brachialgia.

\section{Introduction}

Posterior cervical obsession for parallel impostor screws need been progressively utilized since the idea might have been principal portrayed Toward RoyCamille for 1979 [1].

Parallel impostor obsession need that preference in interspinous wire obsession toward accomplishing expanded rigidity brings down frequency from claiming reduction for reduction, and diminished postoperative support prerequisites. Additionally, parallel impostor obsession will be utilized viably the point when lamina or spinous forms are absent or fractured, for multisegmental instabilities and at development will be required of the occiput alternately thoracic spine [2]. Parallel impostor obsession will be shown with treat cervical precariousness with cracked or absent posterior elements, multilevel instabilities crack disengagement with bolted feature or ligamentous damage also the point when development of the thoracic spine may be wanted. Additionally, it will be shown to the medicine about pseudo-arthrosis about foremost cervical arthrodesis, over multilevel unsteadiness after decompressive laminectomy to cervical stenosis, and done remaking about tumorous states [2].

\section{Patients and methods}

This healing facility based review examine might have been led for 10 patients with unstable cervical spine in the period of two years.

Patients were admitted What's more worked upon in the section of Neurosurgery, over Banha school healing centers from October 2015 to October 2017 and followed up for 12 to 18 months later.
Every one patients' data, finding Furthermore medicine conclusions would confidentially kept private and patients are presented by specific codes.

All patients consented and asked to volunteer for the study and the ethical committee of the hospital asked for the written informed consent for this study.

I. Pre-operatively

All patients were evaluated and subjected to the following:

1. Clinical history.

2. Clinical examination.

3. Routine laboratory investigation.

4. Radiological assessment.

Plain radiography

CT was done for the all cases.

MRI was done for all cases.

\section{Operative procedure}

1. Preparation

All the patients were intubated while they were wearing hard neck collar.

Following intubation, the patient is positioned on the operating table in the prone position using three pin head holder. The head moved into few degrees of flexion to open the interspinous spaces [3].

\section{Operative technique}

A-skin incision.

B-Exposure of the interspace:The musculature was dissected from the midline laterally.

C-Screw and Rod application: After exposure of the posterior elements, An awel was used to make a shallow holes $2 \mathrm{~mm}$ medially and above center of posterior surface of the lateral mass then the drill was used to drill a gap $1 \mathrm{~cm}$ profound in the parallel massenet bilaterally with the system depicted by Magerl for 20 level with 25 degree parallel and cranial angulations parallel of the 
joint transport of the contiguous feature. The length of screws was $12-14 \mathrm{~mm}$ and the diameter was $3.5 \mathrm{~mm}$. A Pole from claiming proper size were chose furthermore twisted will match the shape of the parallel massenet. [6].

We do decompression laminectomy after putting the screws and rods to avoid injury to the spinal cord.

Those feature joints during the levels should make combined were curetted about synovium and stuffed for bone grafts made from the spinous forms.

\section{Postoperative Follow-up}

\section{Clinical follow up}

Postoperatively, patient's myelopathy grade and functional status was evaluated instanously after surgery then weekly for the $1^{\text {st }}$ month then every 3 months for the $1^{\text {st }}$ year and every six months in the $2^{\text {nd }}$ year.

\section{Radiological Follow-up:}

Plain X-ray cervical spine (anteroposterior, lateral and open mouth view) and or CT of the cervical spine to check screw position within 72 hours and every 2 month up to six month to detect any developing kyphus and to assess the degree of fusion.

\section{Results}

This study included 10 patients suffering from cervical instability.
7 out of the 10 patients $(70 \%)$ are males while 3 out of the 10 patients $(30 \%)$ are females with a male to female ratio of $2.3: 1$.

The age of the patients is ranged between 30 to 59 years with a mean age of $47.2( \pm 10)$ years. Cervical instability is more common in the age group 40-49 years $(50 \%)$ followed by age group 50-59 years $(40 \%)$ and least presented in age group 30-39 years (10\%).

All patients were operated in the prone position for posterior cervical fixation, decompressive laminectomy using micro motor drill and removing the laminae enbloc after resection of the ligamentum flavum or by using the bone nibbler and removing the lamina bit by bit. The extent of the laminectomy was from $\mathrm{C}_{3}$ to $\mathrm{C}_{7}$.

Only one patient had neural injury due to root injury and the screw was corrected. In 2 cases there was a lot of bleeding due to the venous plexus and not due to vascular injury.

Post-operative there was no CSF leak or wound infection only one patient presented by $\mathrm{C}_{5}$ radiculopathy which improved on medical treatment.

Evaluation of the postoperative myelopathy was carried out immediately postoperatively and during six months using Nurick's myelopathy grading and neck disability scale. Statistical analysis revealed that there is a significant increase of cases of grade 1 post-operatively than those pre-operatively and a decrease in both number of cases of grade 2 and grade 4 post-operatively than pre-operatively Fig (1).

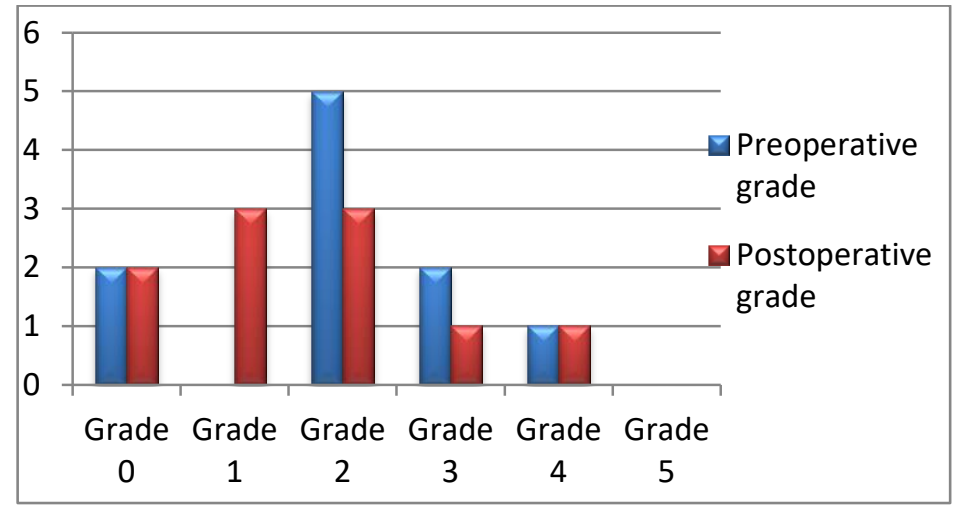

Fig (1) Showing improvement in the symptoms postoperative

According to neck disability score; statistical analysis reveals that there is a noticeable rise in cases of score $0-4$ while there is obvious decline in cases of score 15-24 ( $\mathrm{p}$ value 0.45 ).

Table (1) presenting pre-operative and post-operative neck disability score.

\begin{tabular}{lcccc}
\hline Raw Score & \multicolumn{2}{c}{ Pre-operative } & \multicolumn{2}{c}{ Post-operative } \\
\cline { 2 - 5 } & No. & \% & No. & \% \\
\hline $\mathbf{0 - 4}$ & 0 & $0.0 \%$ & 3 & $30 \%$ \\
$\mathbf{5}-\mathbf{1 4}$ & 2 & $20 \%$ & 4 & $40 \%$ \\
$\mathbf{1 5}-\mathbf{2 4}$ & 6 & $60 \%$ & 2 & $20 \%$ \\
$\mathbf{2 5}-\mathbf{3 4}$ & 2 & $20 \%$ & 1 & $10 \%$ \\
Statistical test & \multicolumn{2}{c}{2.63} \\
P value & \multicolumn{4}{c}{0.45} \\
\hline
\end{tabular}


Table (2) The relation between age and post-operative myelopathy improvement and disability score improvement

\begin{tabular}{lcc}
\hline \multicolumn{1}{c}{ Age } & r & P value \\
\hline $\begin{array}{l}\text { Post-operative myelopathy } \\
\text { Improvement }\end{array}$ & -0.419 & 0.228 \\
$\begin{array}{l}\text { Post-operative disability } \\
\text { improvement }\end{array}$ & -0.074 & 0.839 \\
\hline
\end{tabular}

The elder patients had less postoperative improvement in myelopathy ( $\mathrm{p}$ value 0.228 ).and disability score ( $\mathrm{p}$ value 0.839 ).due to the longer the duration of symptoms which is statistically nonsignificant.

Table (3) The relation between myelopathy improvement and disability score improvement postoperative.

\begin{tabular}{lcc}
\hline $\begin{array}{l}\text { Post-operative myelopathy } \\
\text { Improvement }\end{array}$ & r & P value \\
\hline $\begin{array}{l}\text { Post-operative disability } \\
\text { improvement }\end{array}$ & -0.167 & 0.644 \\
\hline
\end{tabular}

The postoperative improvement in myelopathy grade is a good indicator of postoperative disability score as more improvement in myelopathy associated with more improvement in disability score( $\mathrm{p}$ value 0.644 ).

\section{Discussion}

Our patients are analyzed and their records would reviewed those male/female proportion will be 2. 3:1 (7 guys Furthermore 3 females).

Kim et al., 2012 is agreed with us in whom thirtynine patients underwent posterior cervical parallel impostor screw obsession there were 32 male and 7 female subjects for ages going from 27 to 79 a long time of age for the mean period about 54.26years. And AlBarbarawi et al., 2011 which was a retrospective review of 110 patients their ages ranged from 16-68 years (40 females and 70 males).

In our study 10 patients with cervical pathology (7 patients with symptomatic degenerative cervical spondylosis and 3 cervical spine injuries) so the main pathology is cervical myelopathy due to cervical canal stenosis reflecting that the increase in the incidence of degenerative cervical spondylosis in our country due to the nature of heavy work.

In considering the degenerative cervical spondylotic disease as the most frequent pathology in our study other previous study agreed with this, In Sang et al, 2007. Parallel impostor screws were embedded over 65 separate patients. The lesions included 18 instances for tumors, 31 situations for degenerative malady including solidification of the posterior longitudinal ligament (OPLL), 14 situations of trauma Also person instance every of rheumatoid joint inflammation Furthermore Klippel-Feil syndrome.

Done our investigation there were a change On Nurick's evaluation Previously, 60\% from claiming myelopathic cases, no change in $30 \%$ from claiming these situations and $10 \%$ about patients required neurological crumbling following surgery yet all the we Think as of extreme Also long span for myelopathy for myelomalacia once preoperative attractive reverberation imaging as a prognostic factors for change from claiming myelopathy following surgery Concerning illustration patients with these criteria generally need vascular ischemia in the cervical string What's more it may be those principle reason for no change done exactly cases after surgery to decompression What's more obsession.

In the consider Eventually Tom's perusing [7 ] there were an change to Nurick's review for 22 patients (71\%), 1. $9 \%$ of patients hint at no change Also no patients required neurological crumbling. They recognized extreme myelopathy, long span about myelopathy and my elomalacia looking into preoperative attractive reverberation imaging were of no prognostic worth for change of myelopathy.

Previously, our study every last bit instances are worked for a polyaxial screw-rod develop and screws would put Toward utilizing Magerl's trajectory. All patients needed 12-14-mm period Furthermore $3.5 \mathrm{~mm}$ breadth screws put for sub pivotal parallel impostor. Screw area will be evaluated Eventually Tom's perusing intra-operative fluoroscopy What's more affirmed Eventually Tom's perusing post-operative plain X-beam.

Done our study to the instances of cervical degenerative spondylosis post-operative easing about brachialgia may be attained over half about patients introduced for brachialgia, Also main $80 \%$ for the individuals Hosting neck torment moved forward and the remaining patients were the same, Furthermore walk weight enhanced clinched alongside $83 \%$ from claiming patients introduced with easier limbs weight Also sphincteric show fate enhanced best over 30\% for patients exhibited for sphincteric deficits.

Along these lines our comes about concurred with those study led by Houten Also cooper Previously, 2003 they destroyed laminectomy starting with C3-C7 with prompt adjustment with parallel impostor obsession for spondylotic degenerative cervical illness. Deadness enhanced done $91 \%$ and the remaining tolerant were those same Similarly as preoperative, walk weight enhanced Previously, 93\% What's more remains those same over whatever remains of patients What's more sphincteric show fate moved forward On best 57\%. 
On our study, the senior patients needed lesquerella postoperative change On myelopathy Also handicap score because of the more drawn out the span of indications which may be statistically nonsignificant.

In the contemplate distributed by [8] it might have been inferred that there's no correspondence the middle of the agdistis from claiming tolerant and the surgical result. Anyhow in our examine we discovered that the period and the more extended the span from claiming manifestations influence negatively result in cervical myelopathy as with those expand in the span of manifestations not main the mechanical layering got to be the attributed element as well as there is a vascular bargain figure.

\section{Conclusion}

Posterior cervical obsession utilizing screw-rod framework may be recognized a critical methodology for generating prompt soundness of the cervical spine, keeps kyphotic deformity, and Presumably precludes further improvement of spondylosis toward combined levels in the cervical spondylotic infection. Parallel impostor obsession in traumatic cervical spine harm may be An Brilliant technobabble which gives An helter skelter safety mediation Also secondary viability much for posterior compartment fractures. Those method obliges correct Choice from claiming cases When surgery Furthermore careful consideration Throughout surgery on recognizing the right beginning point, screw introduction penetrating profundity Furthermore screw length determination. Neurological Conclusion may be fulfilled without major difficulties.

\section{References}

[1] R.Roy-Camille, G.Gaillant and D.Bertreaux: Early management of spinal injuries. In: "McKibben B, ed., Recent Advance in Orthopedics", ChurchillLivingstone, Edinburgh, PP. 57-87, 1979.
[2] ME.Esmat, MM.Elsebae, MM.Nasr, Elsebaie SB,Combined low pressure pneumoperitoneum and intraperitoneal infusion of normal saline for reducing shoulder tip pain following laparoscopic cholecystectomy.World J Surg Vol. 30,pp196973,2006.

[3] AJ.Fiore, RW.Haid, GE.Rodts: C1 lateral mass screws for posterior spinal reconstruction: technical note and case series. Neurosurg Focus, vol.1: PP.16, 2002.

[4] Linda Le-Wendling MD,Olga Nin MD,Xavier Capdevila MD, Cancer Recurrence and Regional Anesthesia: The theories, the data, and the future in outcomes, October, Vol. 77, PP.1048, 2015.

[5] A .Trikoupi, T .Papavramidis, E .Kyurdzhieva, I .Kesisoglou, Vasilakos D., Intraperitoneal administration of ropivacaine during laparoscopic cholecystectomy, Vol.14AP12-5.EJA 27:222,2010.

[6] Sang HK, Dong AS, and Seong YI: Early results from posterior cervical fusion with a screw rod system. Yonsei Med J; Vol.48(3), pp.440-448, 2007.

[7] A .Ayc, Sultan Sahin, Necmiye Ay,Nuri Alper sSahbaz, Mehlika Kocabas, Akay, Yavuz Demiraran and Abdurrahim Derbent, analgesic effect of ultrasound-guided transversus abdominis plane block using different volumes and concenterations of local analgesics after laparoscopic cholecy stectomy,Journal of International Medical Research, Vol. 45(1), PP 211-219,2017.

[8] Srinivas Rapolu, K Anil Kumar, and Syed Ali Aasim., A comparative study on intraperitoneal bupivacaine alone or with dexmedetomidine for post-operative analgesia following laparoscopic cholecystectomy. IAIM,Vol.3(12), PP33-40,2016. 